\title{
Aesthetic management of tooth discolouration: conservative treatment for a patient with undifferentiated nasopharyngeal carcinoma
}

\author{
Abordagem estética da descoloração dentária: \\ tratamento conservador de um paciente com carcinoma \\ nasofaríngeo indiferenciado
}

\begin{abstract}
Purpose: Dental aesthetics has considerable impact in our beauty-conscious society. The darkening of the anterior teeth causes concern for adolescents due to the compromised physical appearance. This article presents a clinical case of tooth staining in an individual who had undergone radiotherapy/chemotherapy for an undifferentiated nasopharyngeal carcinoma.

Case description: A 14-year-old boy presented to the dental clinic complaining of pain and staining of the maxillary and mandibular incisors, canines and premolars after having undergone radiotherapy/chemotherapy and stated his desire to remove the dark stains from the surface of the teeth due to his compromised oral aesthetics. Tooth whitening was performed with hydrogen peroxide, followed by micro-abrasion. At a two-year follow-up visit, clinical success was observed and the child was very satisfied.

Conclusion: The adoption of such methods provided efficient alternatives for the re-establishment of a healthy smile, thereby returning pleasing facial aesthetics to the patient. The minimization of distress is nearly always the focus of clinical efforts at promoting psychological health in cancer survivors.
\end{abstract}

Key words: Nasopharyngeal neoplasms; tooth discoloration; tooth bleaching; quality of life

\section{Resumo}

Objetivo: Atualmente, a estética dentária tem um impacto considerável na sociedade. $\bigcirc$ escurecimento dos dentes anteriores causa preocupação para os adolescentes, devido à aparência física comprometida. Este artigo apresenta um caso clínico de descoloração dentária em um indivíduo submetido a radioterapia/quimioterapia para tratamento de um carcinoma indiferenciado de nasofaringe.

Descrição do caso: Um adolescente do gênero masculino, de 14 anos de idade, apresentou-se à clínica odontológica com queixa de dor e pigmentação dos incisivos superiores e inferiores, caninos e pré-molares após ter sido submetido a radioterapia/quimioterapia, declarando seu desejo de remover as manchas escuras na superfície do dentes comprometidos, devido à sua estética bucal. Foi realizado um clareamento dentário com peróxido de hidrogênio, seguido por micro-abrasão. Em um período de dois anos de seguimento, foi observado o sucesso clínico e a satisfação da criança.

Conclusão: A adoção de tais métodos proporciona alternativas eficientes para o restabelecimento de um sorriso saudável, resgatando assim uma imagem facial agradável para o paciente. A minimização do sofrimento é geralmente o foco dos esforços clínicos visando a promoção da saúde psicológica em pacientes que sobreviveram ao câncer.

Palavras-chave: Neoplasias nasofaríngeas; descoloração de dente; clareamento de dente; qualidade de vida

\author{
Ana Carolina Scarpelli a \\ Cristiane Baccin Bendo a \\ João Batista Novaes-Júnior a \\ Ivan Doche Barreiros " \\ Saul Martins Paiva a
}

- Federal University of Minas Gerais, Belo Horizonte, MG, Brazil

\section{Correspondence:}

Cristiane Baccin Bendo

Rua Professor Otaviano, número 131, apto 2002

Bairro Santa Efigênia

Belo Horizonte, MG - Brazil

30260-020

E-mail:crysbendo@yahoo.com.br

Received: April 5, 2010

Accepted: November 22, 2010

Conflict of Interest Statement: The authors state that there are no financial and personal conflicts of interest that could have inappropriately influenced their work.

Copyright: (C) 2011 Scarpelli et al.; licensee EDIPUCRS. This is an Open Access article distributed under the terms of the Creative Commons AttributionNoncommercial-No Derivative Works 3.0 Unported License. 


\section{Introduction}

Dental aesthetics has considerable impact in our beauty-conscious society (1). The appearance of the teeth is determined by socio-cultural values and individual preferences (2). Despite this, criteria for the definition of adequate oral health are determined by dental professionals through objective evaluations based on scientific standards as well as their subjective view of what they consider to be healthy, functional and aesthetically pleasing. Thus, the patient's own perception of his/her oral health status is not even taken into account (3).

Tooth colour is determined by intrinsic and extrinsic colouration. Intrinsic tooth colour is related to the lightscattering and adsorption properties of the enamel and dentin. Extrinsic stains are caused by the absorption of materials contained in cigarettes and dietary intake of tannin-rich foods (e.g. tea, coffee, soft drinks) (1). Extrinsic staining may also be brought about by the occurrence of dry mouth, which is a characteristic of individuals in radiotherapy. The reduction in salivary flow causes an increase in the demineralization potential of the teeth (4), thereby favouring the depositing of stains from external products. However, aesthetically displeasing colouration of the teeth can be managed by bleaching, micro-abrasion, veneering or crowning (5).

This article describes the dental treatment adopted in a clinical case involving tooth staining in an adolescent having undergone treatment for nasopharyngeal carcinoma.

\section{Case Description}

A male individual aged 14 years presented to the dental clinic complaining of pain and staining in maxillary and mandibular incisors, canines and premolars after having undergone radiotherapy/chemotherapy. The patient stated his desire to remove the dark stains from the surface of the teeth, which were compromising his oral aesthetics.

During the patient history, the mother reported that the patient had undergone nasopharyngeal surgery for a biopsy. The anatomopathological exam of the tissue led to the diagnosis of an undifferentiated nasopharyngeal carcinoma and the patient was referred to the oncology department for cancer treatment. While undergoing chemotherapy, the patient also began radiotherapy sessions. Radiotherapy in the cervical-facial region was carried out for a period of two months, together with chemotherapy. The patient has remained under the care of the oncology department since July 2005 and has not exhibited any signs of recurrence following treatment. The adolescent is taking medication that is potentially capable of causing extrinsic stains on the teeth (an iron salt).

During the oral examination, the occurrence of dry mouth and lips was detected. The patient had active carious lesions and cavities in the right and left maxillary second molars, first maxillary left molar, first left premolar, left central incisor, mandibular right, central and lateral incisors. There were brownish-yellow stains in the cervical region of the maxillary and mandibular incisors, canines and premolars. The patient reported the daily ingestion of coffee and soft drinks (Fig. 1).

The treatment adopted was the removal of carious tissue and the definitive restoration of the cavities. With the oral health of the patient re-established, treatment was begun on the stains in the cervical region of the maxillary and mandibular incisors, canines and premolars. For such, whitening of the maxillary and mandibular incisors, canines and premolars was performed, followed by micro-abrasion. Authorization was obtained from the patient and parents for the recording and publication of the clinical case in a scientific periodical.

In the clinical session, the patient was submitted to prior prophylaxis to remove the extrinsic stains and bacterial plaque. Relative isolation of the maxillary and mandibular teeth with a gum protector (Top Dam, FGM, Joinville, SC, Brazil) was then performed in order to avoid contact between the whitening gel and mucosa.

The 35\% hydrogen peroxide-based whitening gel (Whiteness HP, FGM, Joinville, SC, Brazil) was prepared using a proportion of 21 drops of peroxide to seven drops of thickener, which is the necessary amount for an arch (ten teeth), corresponding to the patient's smile line. The whitening gel was administered to the vestibular surface of the teeth and remained in contact with the dental structure for 15 minutes. The gel was then removed with gauze and another application was performed. Upon conclusion of the session, the teeth were washed abundantly with water and the gum protector was removed. The whitening gel was applied in both maxillary and mandibular arches in same session. The patient was submitted to four clinical sessions for whitening, each with three applications of the whitening gel during each clinical session (Fig. 2).

Next, the affected teeth received absolute isolation and were submitted to micro-abrasion using $37 \%$ phosphoric acid (Dentsply, Petrópolis, RJ, Brazil) and pumice stone paste. The paste was applied to the dental structure for six seconds on each tooth. Eight applications were performed on each tooth in a single session. The teeth were then washed with water and the dental dam was removed. Only the surface layers of the enamel were removed in order to preserve the dentine.

Although the stains were not completely removed, the patient and parents were satisfied with the final aesthetic result (Fig. 3).

The patient underwent clinical evaluations of the treatment every six months for a period of two years. Plaque control was satisfactory and there was no report of sensitivity or pain symptoms. Photos of the patient were taken at the 24-month follow-up session. The treatment remained aesthetically acceptable and the patient was very satisfied (Fig. 4). 


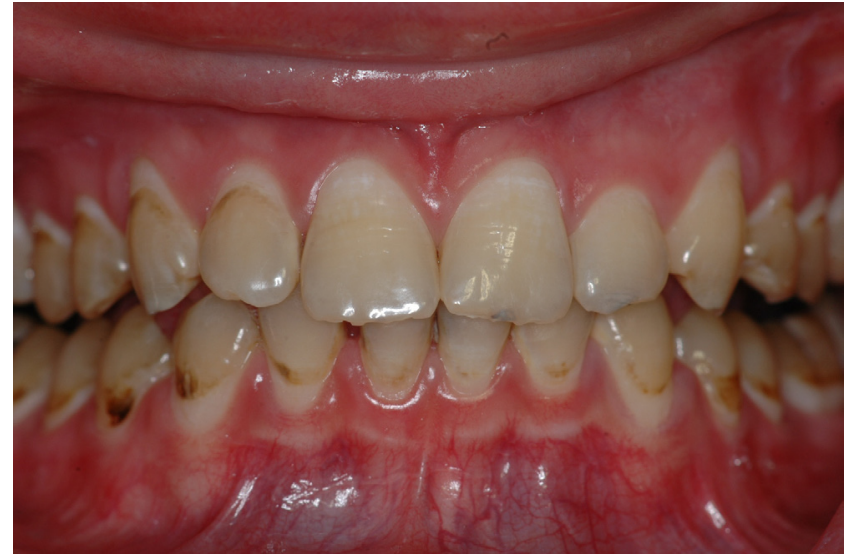

Fig. 1. Yellowish-brown stains in the cervical region of maxillary and mandibular incisors, canines and premolars.

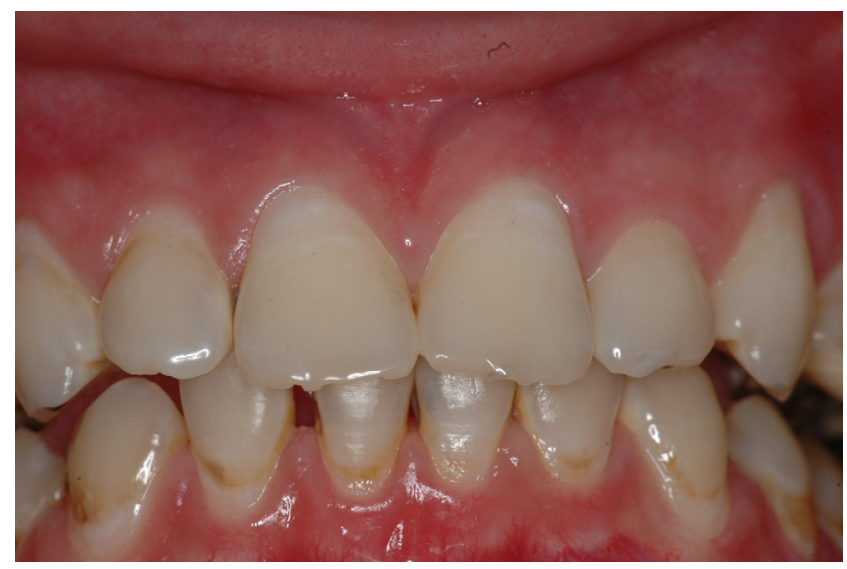

Fig. 3. Appearance of maxillary and mandibular incisors, canines and premolars after whitening and micro-abrasion sessions.

\section{Discussion}

Aesthetics could be an important factor of life in society. Harm to self-esteem during childhood and adolescence may affect interpersonal relationships and identification with a group, leading to feelings of inferiority and isolation from social life (6). Thus, dentists should be capable of assessing individual patient needs based on perceived needs and impact in order to establish suitable treatment plans and obtain the best treatment outcomes (7). Children and adolescents have their own concepts of what is healthy or unhealthy, satisfactory or unsatisfactory, and are able to identify their oral health problems (3).

In the case presented here, the patient was psychologically vulnerable due to his general health condition. Moreover, dental lesions stemming from caries and dental erosion as well as conditions such as dry mouth and vomiting as a consequence of chemotherapy/radiotherapy led to discomfort.

The long-term effects of cancer treatment on body image and physical health remain a special concern for cancer

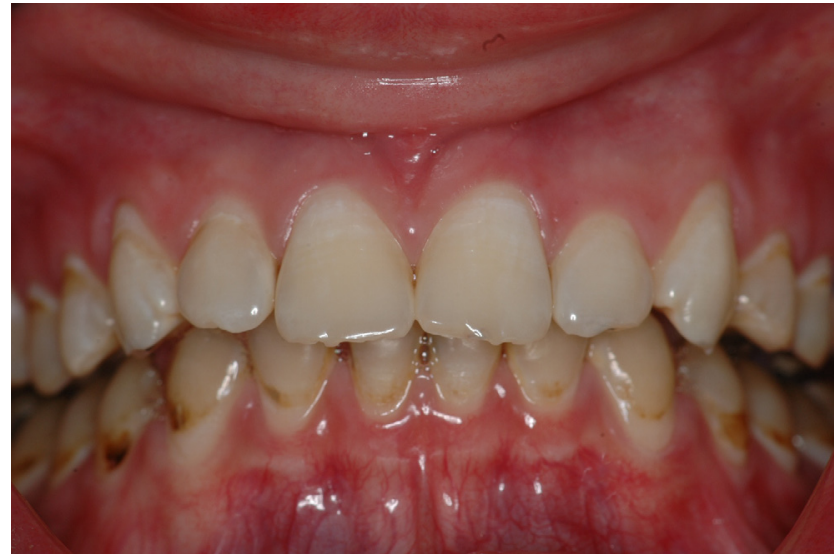

Fig. 2. Appearance of maxillary and mandibular incisors, canines and premolars after whitening sessions.

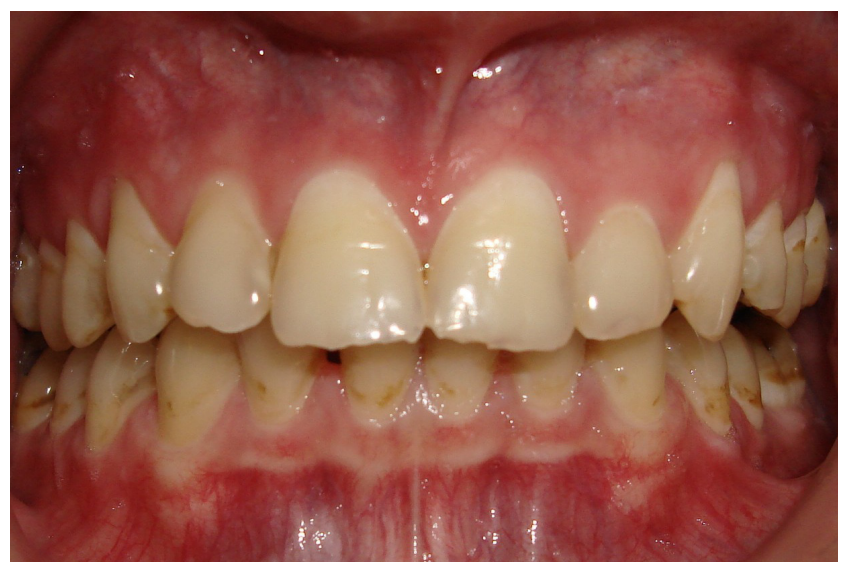

Fig. 4. Appearance of maxillary and mandibular incisors, canines and premolars two years after treatment.

survivors. Social support and psychosocial adaptation have been shown to have a positive effect on adolescents with cancer (8). Chemotherapy/radiotherapy has significant negative effects on an individual's health. Chemotherapy often causes nausea and vomiting, making eating one of the greatest difficulties such patients face (9). Gastroesophageal reflux may result in dental erosion as a consequence of acidity from the gastric fluid in the oral cavity. Radiotherapy has common side effects such as dry mouth, dysphagia and fibrosis. It also compromises the integrity of the oral mucosa, resulting in pain, loss of the sense of taste, difficulty in eating and sleep disorders (10).

All these conditions led the patient to experience pain, dental caries, staining of the teeth and dry mouth. The dental decalcification caused by constant presence of gastric acid in the oral cavity due to vomiting, the reduction in salivary flow and the excessive intake of products with tannins possibly contributed to the staining of the patient's teeth (11). During cancer treatment, the patient's eating habits underwent a significant change due to the difficulty in ingesting foods 
caused by nausea and alterations in the sense of taste (12). Thus, a lack of control over food intake occurred, as any type of food that the patient was able to ingest was considered nutritionally important. In the case presented, there was permissiveness on the part of the parents regarding the adolescent's eating habits while he was in cancer treatment and the intake of soft drinks, candy and coffee was increased, thereby favouring oral conditions such as carious dental lesions and extrinsic stains.

The aim of the clinical management of tooth discolouration is to produce an acceptable cosmetic result as conservatively as possible. Tooth whitening and microabrasion are considered the first choice, as these procedures are able to reduce discolouration and provide satisfactory results (13). For tooth whitening, the most often employed agents are hydrogen peroxide and carbamide peroxide, which can be used either at the dental clinic or at home (night whitening). In the case presented here, the patient was submitted to whitening at the dental clinic using $35 \%$ hydrogen peroxide as the whitening gel. Hydrogen peroxide is capable of dissolving organic and inorganic compounds, thereby providing the whitening of the dental structure (14). As the bleaching process using the whitening gel was not sufficient for the complete removal of the stains, mainly in mandibular teeth, there was the need to perform microabrasion. During this process, the surface layers of the enamel are gradually removed using an acid compound until reaching an intact enamel surface. Rigorous control of the abrasion depth is necessary so as not to expose the dentin (13).

In summary, the darkening of the anterior teeth caused concern for the adolescent due to his compromised physical appearance. The administration of whitening and microabrasion methods proved efficient in re-establishing the dental aesthetics. The psychosocial benefits of treatment include enhanced self-esteem and a reduction in social anxiety. The occurrence of childhood cancer implies restrictions to daily living. Emotional disorders and psychological effects, such as a diminished capacity for social interaction, can be attributed to the therapy (15). In this context, the improvement of quality of life through better functioning and psychosocial wellbeing is the greatest benefit of dental care, especially in patients with special needs.

\section{Acknowledgments}

This study received support from the National Council for Scientific and Technological Development (CNPq), Ministry of Science and Technology, and from the State of Minas Gerais Research Foundation (FAPEMIG), Brazil.

1. Joiner A. The bleaching of teeth: a review of the literature. J Dent 2006;34:412-9.

2. Vallittu PK, Vallittu ASJ, Lassila VP. Dental aesthetics - a survey of attitudes in diferent groups of patients. J Dent 1996;24:335-8.

3. Meneghim MC, Kozlowski FC, Pereira AC, Assaf AV, Tagliaferro EP. Perception of dental fluorosis and oral health disorders by 12-year-old Brazilian children. Int J Paediatr Dent 2007; 17:205-10.

4. Bardow A, Nyvad B, Nauntofte B. Relationships between medication intake, complaints of dry mouth, salivary flow rate and composition, and the rate of tooth demineralization in situ. Arch Oral Biol 2001;46:413-23.

5. Abdollahi M, Rahimi R, Radfar M. Current opinion on drug-induced oral reactions: a comprehensive review. J Contemp Dent Pract 2008;9:1-15.

6. Elias MS, Cano MA, Mestriner Júnior W, Ferriani MG. Importance of oral health for adolescents from different social levels in the municipality of Ribeirao Preto. Rev Lat Am Enfermagem $2001 ; 9: 88-95$

7. Gherunpong S, Tsakos G, Sheiham A. A sociodental approach to assessing dental needs of children: concept and models. Int J Paediatr Dent 2006;16:81-8.

8. Cantrell MA, Lupinacci P. Investigating the determinants of health-related quality of life among childhood cancer survivors. J Adv Nurs 2008;64:73-83.

9. Oates JE, Clark JR, Read J, Reeves N, Gao K, Jackson M et al. Prospective evaluation of quality of life and nutrition before and after treatment for nasopharyngeal carcinoma. Arch Otolaryngol Head Neck Surg 2007;133:533-40.

10. Tredwin CJ, Scully C, Bagan-Sebastian JV. Drug-induced disorders of teeth. J Dent Res 2005;84:596-602.

11. Valena $V$, Young WG. Dental erosion patterns from intrinsec acid regurgitation and vomiting. Aust Dent J 2002;47:106-15.

12. Berteretche MV, Dalix AM, d'Ornano AM, Bellisle F, Khayat D, Faurion A. Decreased taste sensitivity in cancer patients under chemotherapy. Support Care Cancer $2004 ; 12: 571-6$.

13. Araujo FB, Zis V, Dutra CAV. Enamel colour change by micro-abrasion and resin-based composite. Am J Dent 2000;13:6-7.

14. Joiner A. Review of the effects of peroxide on enamel and dentine properties. J Dent 2007:35:889-96.

15. Scarpelli AC, Paiva SM, Pordeus IA, Ramos-Jorge ML, Varni JW, Allison PJ. Measurement properties of the Brazilian version of the Paediatric Quality of Life Inventory (PedsQL) cance module scale. Health Qual Life Outcomes 2008;6:7. 